\title{
Arteriovenous Fistula after Femoral Artery Puncture Leading to Pulmonary Edema: The Role of Ultrasonography
}

\section{Malík J., Holaj R., Krupičková Z., Janota T.}

3rd Department of Medicine - Department of Endocrinology and Metabolism, First Faculty of Medicine, Charles University in Prague and General University Hospital in Prague, Prague, Czech Republic

Received July 6, 2011; Accepted January 16, 2012.

Key words: Arteriovenous fistula - Doppler ultrasonography - Vascular access

Abstract: Local complications of arterial puncture include hematoma, pseudoaneurysm and formation of arteriovenous fistula (AVF). The latter could cause ischemia of the particular extremity or can be hemodynamically significant especially in patients suffering from congestive heart failure. We report a case of femoro-femoral AVF after thin needle arterial puncture for blood drawing. The development of this iatrogenic AVF led to pulmonary edema. The patient stabilized completely after surgical closure of the AVF. The AVF was diagnosed by duplex Doppler ultrasonography and this method was also used for estimation of blood flow through the AVF. We discuss the role of ultrasound AVF diagnostics and the method of flow calculation.

This study was supported by the Internal Grant Agency of Ministry of Health of the Czech Republic NS 10590-3.

Mailing Address: Assoc. Prof. Jan Malík, MD., PhD., 3rd Department of Medicine - Department of Endocrinology and Metabolism, First Faculty of Medicine, Charles University in Prague and General University Hospital in Prague, U nemocnice 1, 12808 Prague 2, Czech Republic; Phone: +420 224962 363;

e-mail: malik.jan@vfn.cz 


\section{Introduction}

Local complications of the femoral artery puncture include development of hematoma, pseudoaneurysm and arteriovenous fistula (AVF) (Malíková and Cholt, 1999; Craig and Taylor, 2002). Their risk increases with anticoagulation or antiaggregation therapy. Local complications are more likely in case of inappropriate removal of the canulla or needle. Typically, they are associated with the use of large diameter devices, such as sheath for angiography.

AVF is a rare complication of arterial cannulation. The hemodynamic impact of AVF has been studied especially in surgically formed AVFs - i.e. hemodialysis vascular accesses. Creation of the vascular access could lead to the worsening of already present heart failure, such as in patients with systolic dysfunction of the left ventricle. We report an unusual case of heart failure de-compensation due to iatrogenic AVF after fine needle femoral artery puncture and the value of ultrasonography for estimation of AVF flow, which helped to choose the best treatment strategy.

Arterial cannulation is not the only cause of AVF. The others include trauma, congenital AVF, inflammation (abscesses).

\section{Case report}

A 79-year-old lady was admitted to the Coronary Care Unit because of shortness of breath. She had the history of myocardial infarction 15 years ago, treated noninvasively (no history of arterial puncture). At admission, she was febrile $\left(37.7^{\circ} \mathrm{C}\right.$ ), had unilateral basal pulmonary rales, elevated leukocyte count $\left(15.2 \times 10^{9} / \mathrm{l}\right.$, normal values lower than 10) and serum C-reactive protein $(80 \mathrm{mg} / \mathrm{l}$, normal values lower than $10 \mathrm{mg} / \mathrm{I})$. Spontaneous oxygen saturation was $84 \%$. Blood coagulation factors were normal: INR 1.0, aPTT $31 \mathrm{~s}$, platelets $180 \times 10^{9} /$. She took $100 \mathrm{mg}$ aspirin daily. Chest $\mathrm{X}$-ray suspected both pulmonary congestion and right side basal bronchopneumonia. On echocardiography, the left ventricle was not dilated and its ejection fraction was $30 \%$ together with mild mitral valve regurgitation. The estimated cardiac output was $2.8 \mathrm{I} / \mathrm{min}$. Antibiotic and mucolytic therapy was initiated together with the prophylactic dose of low-molecular weight heparine (enoxaparine $20 \mathrm{mg} / 24$ hours s.c.). Next morning, femoral artery blood sample was drawn for the blood gases analysis using a thin needle $(0.8 \times 40 \mathrm{~mm}=2$ French $=$ 21 Gauge). Femoral artery was chosen because of weaker pulse on radial arteries and manual compression was applied for 3 minutes. The puncture was easy and arterial blood was drawn during the first attempt. The results were as follows: $\mathrm{pH} 7.356$, oxygen saturation 93\% (with nasal oxygen $6 \mathrm{I} / \mathrm{min}$ ), $\mathrm{pCO}_{2} 6.5 \mathrm{kPa}$ and actual bicarbonates $24.5 \mathrm{mmol} / \mathrm{l}$. The patient's status worsened within the next hour: hypotension developed together with the progression of dyspnoea. Oxygen saturation (by pulse oxymetry) decreased from $94 \%$ to $88 \%$ with the same flow of nasal oxygen $(6 \mathrm{l} / \mathrm{min})$. Another chest $\mathrm{X}$-ray documented pulmonary edema. Intravenous furosemide was administered and the patient needed continuous catecholamines. 
The patient reported pain at the site of the arterial puncture, where also a murmur was audible (not present at admission). Duplex Doppler ultrasonography revealed AVF in the site of the puncture. In the punctured femoral artery, there was low-resistant pattern of the spectral Doppler flow curve above the AVF and high-resistant pattern below the AVF. We measured three times femoral artery flow volume above the AVF - the mean value was $500 \mathrm{ml} / \mathrm{min}$. The flow through the contralateral femoral artery was $60 \mathrm{ml} / \mathrm{min}$ and the flow pattern was high-resistant. The periphery of the punctured leg was colder, but not painful. We concluded that the AVF contributed to the heart failure decompensation and hypotension, because of known low cardiac output $(2.8 \mathrm{l} / \mathrm{min})$. The patient underwent surgical closure of the AVF. Her status improved rapidly and catecholamines were no more needed.

\section{Discussion}

Our case report shows that hemodynamically significant AVF might develop also after fine needle puncture of the femoral artery. Duplex Doppler ultrasonography helps not only in the diagnostics of AVF, but also may help to quantify the blood flow volume through the AVF (Figure 1).

To the best of our knowledge, this is the first published case of hemodynamically significant AVF after fine needle femoral artery puncture, leading to pulmonary oedema. The punctured femoral artery had huge hyperechoic (calcified)

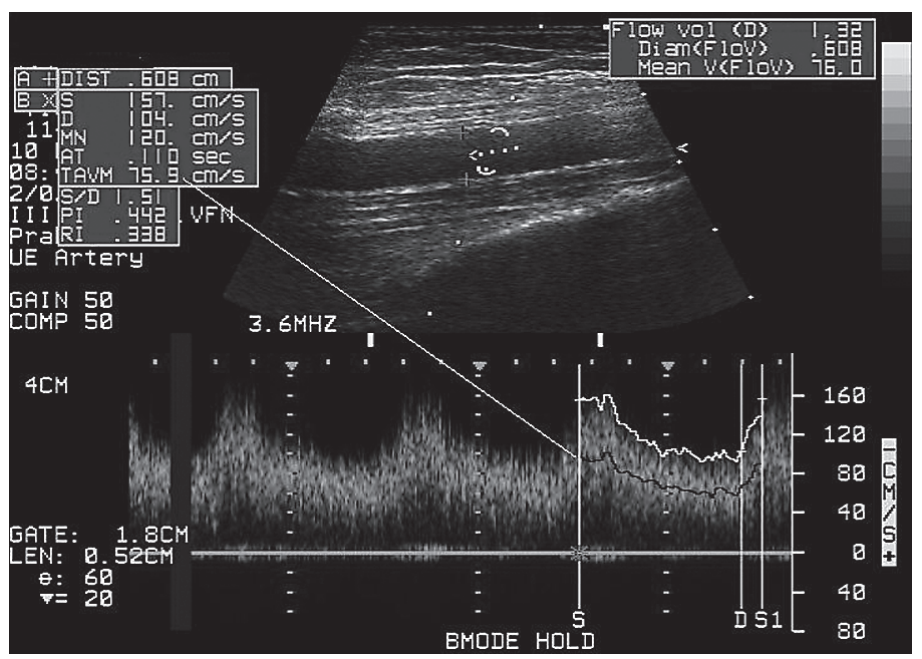

Figure 1 - Access flow calculation by ultrasonography.

The vascular flow should be measured in a straight segment without excessive irregularities (plaques). It is important to avoid significant pressure on the examined vessel. The calculation of flow volume is based on the following equation: $Q=\pi \times r^{2} \times$ TAVM, where " $r$ " means the vessel radius and "TAVM" is time-averaged velocity integral of mean velocity (black curve). It is recommended to measure the flow at least three times and to calculate the mean value of these measurements. We have validated the ultrasound measurement of access flow against the ultrasound dilution technique (Lopot et al., 2004). 
atherosclerotic plaques and trauma of one of these plaques by the needle probably explains the development of such hemodynamically significant AVF. Alternatively, several small arteriovenous communications might develop during the aspiration of the blood. Slight anticoagulation probably also played a role.

Hemodynamic significance of AVF is estimated by the possible development of heart failure decompensation or of peripheral ischemia. There is no concrete value of AVF flow volume predicting hemodynamic significance. It rather depends on patient's cardiac output/heart disease and general condition. Hemodialysis vascular access flow is thought to be safe if it is lower than $1 / 3$ of cardiac output (Bourquelot, 2001) in patients free of heart failure. Even lower flow volume could cause heart failure decompensation in severely ill patients.

Non-significant, small AVFs usually heal spontaneously, while the larger should be treated actively. Stentgrafts (covered stents) are used for the treatment in some centers. They have theoretical advantage of less invasive (and more expensive) procedure.

\section{References}

Bourquelot, P. (2001) High flow - surgical treatment. Blood Purif. 19, 130-131.

Craig, P. A., Taylor, D. S. (2002) The utility of ultrasound in a case of femoral artery pseudoaneurysm and femoral arteriovenous fistula. J. Emerg. Med. 22(3), 291-292.

Lopot, F., Nejedly, B., Sulkova, S., Blaha, J. (2004) Comparison of different techniques of hemodialysis vascular access flow evaluation. J. Vasc. Access 5(1), 25-32.

Malíková, H., Cholt, M. (1999) Ultrasonographical findings in the groin after femoral artery puncture. Cor Vasa 44(7), 321-324. 